\title{
ТОРГОВЫЙ РОБОТ НА ОСНОВЕ ИНДИКАТОРА RELATIVE STRENGTH INDEX (RSI)
}

\author{
(c) 2020 Папуша Софья Ильинична \\ Департамент анализа данных, принятия решений и финансовых технологий \\ Финансовый университет при правительстве Российской Федерации, Россия, Москва \\ E-Mail: sofia.papusha@gmail.com \\ ORCID: https://orcid.org/0000-0002-5871-1230
}

Финансовый рынок позволяет работать с большим количеством индикаторов и торговых роботов, основанных на данных индикаторах. Индекс RSI был разработан в 1978 году и показывает силу тренда и вероятность его смены. Большинство роботов, основанных на индикаторе RSI, не имеют постоянной доходности и зависят от определённых ситуаций на рынке - так называемых, зон перекупленности и перепроданности. При этом вне этих зон данные роботы не совершают никаких транзакций, если их алгоритм опирается только на данный индикатор. Таким образом, данные роботы дают какую-либо доходность только на больших выборках, когда индикатор в принципе входит в зоны перекупленности или перепроданности. Вне этих зон данные роботы не дают никаких рекомендаций и не совершают транзакций. На маленьком временном периоде такой робот будет бессмысленным. Целью работы было создать робота, который способен совершать транзакции вне этих зон с прибылью, превышающей инфляцию и ставку ЦБ по вкладам. Был разработан и протестирован робот, позволяющий не только учитывать зоны перекупленности и перепроданности, но и давать рекомендации о покупке и продажи акций вне этих зон. Алгоритм работы робота заключается в следующем: при выходе из зоны перепроданности или перекупленности, робот покупает или продаёт максимальное количество акций соответственно. Для корректной роботы следует протестировать робота на большой выборке, чтобы задать корректные вводные данные, на которых он в последующем будет работать. Также представлены тестовые и контрольные выборки, с помощью которых была выяснена целесообразность использования такого робота. Робот всё ещё имеет несколько минусов: для работы требуется тестовая выборка, при этом предположение, что контрольная выборка будет вести себя также и значения, которые дают прибыль на тестовой выборке, будут давать прибыль на контрольной, не всегда верно.

Ключевые слова: индикаторы, индекс RSI, торговые роботы, финансовый рынок, тренд, осциллятор, арбитраж, торговля на финансовых рынках, трейдер.

\section{Введение}

Финансовый рынок имеет большое количество различных индикаторов, каждый из которых оценивает какую-либо сторону рынка. Анализ различных финансовых индикаторов позволяет понять, когда следует продавать или покупать определённый вид акций, как изменится акция в ближайшее время, факт того, что цена изменится и тому подобное. Это позволяет участникам рынка принимать решения, которые приводят к увеличению капитала и/или уменьшению рисков [3].

В числе прочих, основными индикаторами, используемыми на финансовом рынке, являются:

- CCI (Consumer Confidence Index) - доверие потребителей СB;
- CPI (Consumer Price Index) - индекс Потребительских Цен (ИПЦ);

- Unemployment Rate - коэффициент безработицы (США);

- FOMC Meeting (Interest Rate Decision) - заседание Федерального комитета открытого рынка FOMC (объявление о процентной ставке);

- GDP (Gross Domestic Product) - валовой внутренний продукт (ВВП);

- ISM (Institute for Supply Management) Manufacturing Index - Индекс Производственной Активности;

- MCSI (Michigan Consumer Confidence Index) - индекс настроения потребителей Мичиганского Университета;

- NFP (Changes in non-farm payrolls) - изменение числа занятых в несельскохозяйственном 
секторе;

- Manufacturing PMI (Purchasing Managers Index) - индекс производственной активности PMI;

- Retail Sales Data - данные по розничным продажам;

- Tankan Large Manufacturers Index - индекс производственной конъюнктуры Tankan;

- TIC Net Long-Term Transactions - объем покупок долгосрочных ценных бумаг ТIC;

- Trade Balance - торговый баланс.

Для осуществления целей торговли, трейдерам приходится следить за несколькими индексами и их поведением. Даже в условиях автоматического подсчёта индексов, трейдер всё равно сам принимает решения и на их основе совершает транзакции на финансовом рынке. Имеются множество моделей финансовых рынков и вычислительных алгоритмов для подсчёта компонентов хеджирующего портфеля платежных обязательств в финальный момент времени на финансовых рынках, например в [8-9]. Для финансовых рынков с бесконечным числом состояний, где каждое состояние описывает возможное событие на рынке, такие алгоритмы опираются на результаты из [10].

Торговые роботы - это алгоритм анализа рынка, который способен, на основе полученных данных, самостоятельно совершать сделки на рынке. Безусловное преимущество таких роботов в том, что они работают круглосуточно, анализируют множество информации автоматически, без участия трейдера, исключают любые ошибки в расчётах, которые может совершить человек и самостоятельно принимают решения о покупке или продаже акций, на основе полученных данных [5].

Конкретно индикатор RSI обычно используют для определения «перекупленности» или «перепроданности» акций. Если акция «перекуплена», значит цена на неё в данный момент является максимальной, так как в скором времени акцию перестанут покупать и цена начнёт падать, то есть спрос на данную акцию упадёт. Если же акция «перепродана», значит её цена, скорее всего, начнёт расти в ближайшее время, так как продавать её некоторое время не будут, то есть предложение этой акции будет падать. Это основной способ использования данного индикатора. Тем не менее, он также предсказывает падение или рост акции и вне этих зон - чем выше индикатор, тем выше будет цена.
Индикатор отображает скорость и амплитуду, с которой меняется движение цены. С помощью данного индикатора анализируются сила или слабость текущего рыночного состояния цены. Он меняется от 0 до 100, при этом чем ближе он к 0, тем активнее движение цены вниз ослабевает и наоборот - чем ближе индикатор к 100, тем больше замедляется движение цены вверх [1].

Зона «перекупленности» начинается обычно со значения индикатора от 70. Соответственно, «входом» в данную зону называется повышение индикатора выше 70, а «выходом» - понижение ниже 70. При это продавать акцию стоит именно при выходе из зоны «перекупленности».

Соответственно, зона «перепроданности» находится в диапазоне от 0 до 30. Выходом из этой зоны называется повышение индикатора выше 30, входом - понижение ниже 30. Покупать акцию, также, как и в ситуации с «перекупленностью», следует при выходе из зоны «перепроданности».

Формула индикатора следующая:

$R S I=100-100 /(1+R S)$, где $R S$ = средний прирост / среднее падение. При этом используется метод скользящей средней, обычно используя 14 значений. Есть возможность использовать большее количество значений или меньшее. Чем меньше значений используется в методе скользящей средней, тем больше шумов будет появляться на графике индикатора, но и больше информации. Соответственно, при увеличении количества значений наоборот - меньше шумов, меньше информации.

\section{Роботы на основе индикатора RSI.}

На финансовых рынках, для упрощения работы с данным индикатором, существует множество роботов. Основной принцип работы этих роботов - покупка и продажа акций при выходе индикатора из зоны «перепроданности» или «перекупленности» соответственно. Тем не менее, это единственная функция, которые данные роботы выполняют - такие программы не анализируют ситуацию вне этих зон, не дают никаких советов или указаний для покупки или продажи вне зон «перекупленности» или «перепроданности». Данные роботы имеют смысл только при условии, что акция вообще будет входить в данные зоны - если акция за период использования робота ни разу не войдёт в зону «перепроданности», робот не сможет принять решение о покупке акций. То же самое с обратной зоной - робот будет вечно держать на руках 
определённое количество акций, так как не будет благоприятных, по мнению алгоритма, условий для их продажи.

K сожалению, нет возможности более подробно описать алгоритм работы существующих роботов на основе данного индекса, так как все они являются коммерческими. Базово - робот активизируется только в зонах перекупленности или перепроданности. Вне этих зон робот способен совершать какие-либо операции только при совмещении нескольких индексов в одном алгоритме [6].

\section{Усовершенствованный робот}

Мною был разработан робот, основанный на индикаторе RSI. Особенность данного робота заключается в том, что он позволяет получать рекомендации о покупке или продаже акции вне зон «перекупленности» или «перепроданности акции». Алгоритм основан на следующем тезисе: если индикатор растёт, стоит продавать акцию, так как в скором времени будет падать. Причём продавать следует прямо пропорционально индикатору: чем выше растёт индикатор, тем больше акций робот посоветует продать. При входе в зону «перепроданности» робот останавливает свою работу и ждёт, когда индикатор выйдет из этой зоны. В этот момент алгоритм потребует продать все имеющиеся акции. Соответственно, похожий порядок действий при падении индикатора: чем ниже падает индикатор, тем больше акций следует купить. При входе в зону «перекупленности» алгоритм также останавливается и ждёт выхода из зоны, чтобы скупить акции на все возможные деньги. При этом существует максимум акций, которые можно скупить или продать вне зон перекупленности или перепроданности, а также дополнительное количество акций, которое в любом случае будет куплено или продано при совершении операций вне этих зон.

Такой подход обеспечивает трейдера постоянным притоком и оттоком акций. Это позволяет с одной стороны иметь акции для продажи или деньги для покупки акций при выходе из критических зон, а с другой получать прибыль вне зависимости от того, достигнет ли индикатор вообще критических зон. Естественно, при совершении любых транзакций, алгоритм проверяет, имеются ли средства для совершения покупки или акции в нужном количестве для совершения продажи.

Целью создания данного робота было улуч- шение имеющегося алгоритма работы роботов и повышение доходности. Программа минимум чтобы доход был выше имеющейся инфляции, а также существующей ставки банковских вкладов от ЦБ, так как лишь в этом случае имеет смысл внедрять робота [2]. В таком случае вложение денег в акции и использование данного робота будет более прибыльно, чем просто положить деньги в банк под процент.

При этом мы имеем две выборки: тестовую и контрольную. На тестовой выборке мы подбираем значения для расчётов на контрольной выборке. Таким образом, мы гарантируем, что, если акция не поменяет своего поведения, доходность по ней будет максимальной. Данные подбираются эмпирически.

Вводные данные:

$R S I_{t}$ - значение индекса в данный момент времени;

$N_{-}$- максимальное число продаваемых единовременно акций;

$N_{+}$- максимальное число покупаемых единовременно акций;

$n_{+}-$число дополнительно купленных акций;

$n_{-}$- число дополнительно проданных акций;

$b_{t}$ - цена акции в данный момент времени;

$K_{t}-$ доступный капитал;

$m_{t}-$ количество акций в данный момент;

$r_{\text {- }}$ - рекомендуемое для продажи число акций;

$r_{+}-$рекомендуемое для покупки число акций;

$x_{\max }-$ нижняя граница зоны перекупленности (обычно равна 70\%);

$x_{\min }-$ верхняя граница зоны перепроданности (обычно равна 30\%);

Нейтральная зона - зона индикатора, в которой робот не совершает никаких операций. Обычно это зона, когда индикатор равен 50\%.

$x_{a m a x}-$ верхняя граница нейтральной зоны;

$x_{a m i n}-$ нижняя граница нейтральной зоны.

Если индекс был выше уровня перекупленности, а сейчас уровень ниже этой зоны, то робот продаёт все имеющиеся акции:

$$
R S I_{t-1} \geq x_{\max }, R S I_{t}<x_{\max } \Rightarrow m_{t}=0 ;
$$

Если индекс был ниже уровня перепроданности, а сейчас уровень выше этой зоны, то робот покупает акции на все имеющиеся средства:

$$
R S I_{t-1} \leq x_{\text {min }}, R S I_{t}>x_{\text {min }} \Rightarrow m_{t}=m_{t-1}+K_{t} / b_{t} ;
$$


Количество акций, которые робот продаёт или покупает в зависимости от уровня индекса:

$$
\begin{aligned}
& r_{-}=-\left[N_{-} * \frac{R S I_{t}}{100}\right]-n_{-} ; \\
& r_{+}=\left[N_{+} * \frac{R S I_{t}}{100}\right]+n_{+} ; \\
& x_{\text {amax }}<R S I_{t}<x_{\text {max }} \Rightarrow m_{t}=r_{-}+m_{t-1} ; \\
& x_{\text {min }}<R S I_{t}<x_{\text {amin }} \Rightarrow m_{t}=r_{+}+m_{t-1} ;
\end{aligned}
$$

Если индекс находится в нейтральной зоне, робот не совершает никаких действий:

$$
\begin{aligned}
& x_{\text {amin }}<R S I_{t}<x_{\text {amax }} \Rightarrow m_{t}=0 ; \\
& K_{t}=r * b_{t}+K_{t-1},
\end{aligned}
$$

При этом задаём также следующие критерии:

$$
\begin{aligned}
& K_{t} \Rightarrow \max ; \\
& N_{-}, N_{+}, n_{-}, n_{+}-\text {целые. }
\end{aligned}
$$

Изменяем параметры $x_{\max }, x_{\min }, x_{a \max }, x_{a \min }$, $N_{-}, N_{+}, n_{-}, n_{+}$, чтобы максимизировать итоговое значение дохода. Алгоритм работает в MS Excel.

Для тестовой выборки берем цены акций с 03.01.2019 по 30.09.2019 следующих 5 компаний: Лукойл, М. Видео, МТС, Ростелеком, Сбербанк.

В результате проведённых операций, эмпирически получены наборы параметров, показанные в таблице ниже.

Полученные на тестовой выборке результаты показывают, что алгоритм даёт возможность получить доходность до 20 процентов на тестовой выборке. При этом инфляция с января по октябрь равна $2.39 \%$, а ставка, рекомендуемая ЦБ, составляла от 7 до 7.5\%. Два вида активов абсолютно не удовлетворяют заданным условиям. Применим к тестовой выборке алгоритм, который используют большинство роботов - то есть продажа всех возможных акций при выходе из зоны «перекупленности» и покупка на все деньги при выходе из зоны «перепроданности»:

- Лукойл: $-0,357 \%$
- М.Видео: $-0,98 \%$

- MTC: $11,06 \%$

- Ростелеком: 1,401\%

- Сбербанк: 2,266\%

Таким образом, можем сделать однозначный вывод, что стратегия имеющихся роботов на тестовой выборке не выдерживает никакой критики: только один из активов вышел в плюс относительно инфляции и ставки по вкладам. Остальные же ушли в минус, как по инфляции, так и фактически. Это означает, что при бездумном использовании существующих торговых роботов было бы прибыльнее просто положить деньги в банк под проценты. В некоторых случаях средства были не только не преумножены, но и частично потеряны.

Теперь перейдём на контрольную выборку. Рассчитаем по полученным значениям параметров выигрыш для ноября и декабря по тем же акциям. При переходе на контрольную выборку получим следующие значения доходностей:

- Лукойл: 3,514\%

- М.Видео: 8,778\%

- MTC: $10,555 \%$

- Ростелеком: $-0,147 \%$

- Сбербанк: 2,216\%

Учитывая то, что официальный уровень инфляции с ноября по декабрь 2019 года составлял 0,64\%, четыре из пяти компаний, для которых работал разработанный алгоритм, оказались успешны относительно инфляции. Тем не менее, ставка по вкладам в тот период составляла $6,5 \%$. При пересчёте на месячную ставку, составляла $1,104 \%$. Соответственно, четыре из пяти компаний также показали более высокую доходность относительно ставки по вкладам, рекомендованной ЦБ.

Рассчитаем теперь также для тестовой выборки доход при использовании стандартных роботов для данного индикатора:

- Лукойл: $-1,293 \%$

- М.Видео: 0\%

- MTC: 0\%

- Ростелеком: 0\%

- Сбербанк: $0 \%$.

\begin{tabular}{|l|c|c|c|c|c|c|c|c|c|}
\hline \multicolumn{1}{|c|}{ Тиккер } & $N_{-}$ & $N_{+}$ & $n_{-}$ & $n_{+}$ & $x_{\max }$ & $x_{\min }$ & $x_{\text {amax }}$ & $x_{\text {amin }}$ & Доходность \\
\hline Лукойл & 30 & 30 & 45 & 45 & 70 & 30 & 50 & 50 & $21,6 \%$ \\
\hline М.Видео & 12 & 12 & 1 & 5 & 70 & 30 & 55 & 50 & $3,61 \%$ \\
\hline МТС & 1 & 5 & 0 & 5 & 70 & 30 & 55 & 46 & $11,26 \%$ \\
\hline Ростелеком & 30 & 30 & 22 & 11 & 70 & 30 & 53 & 51 & $8,93 \%$ \\
\hline Сбербанк & 1 & 20 & 0 & 4 & 70 & 30 & 50 & 50 & $14,92 \%$ \\
\hline
\end{tabular}


Такие значения объясняются очень просто: за период в два месяца индикатор ни разу не входил в зону перепроданности, соответственно, робот не купил ни одной акции. Таким образом, можем сказать, что на коротких периодах времени стандартные роботы для индикатора RSI не работают вовсе, а на длинных часто работают в убыток.

\section{Выводы}

Созданный в ходе данной работы алгоритм способен демонстрировать доходность, компенсирующую инфляцию и превышающую ставку, рекомендованную ЦБ. Более того, данный алгоритм имеет огромное преимущество перед используемыми в данный момент на рынке роботами: даже при отсутствии зон «перекупленности» или «перепроданности», он совершает транзакции, которые в итоге ведут к минимальному, но доходу.

Существующие в данный момент на финансовых рынках роботы совершают транзакции только при взаимодействии индикатора с зонами перекупленности или перепроданности. Вне этих зон алгоритмы данных роботов бессильны без подключения каких-либо других индикаторов рынка. Созданный мной робот способен совершать транзакции вне этих зон, получая по- стоянный приток и отток акций с получением прибыли.

Тем не менее, при всех плюсах данного алгоритма, он имеет некоторые минусы:

- Требуется большая тестовая выборка для расчёта параметров работы алгоритма;

- Робот способен работать только после предварительной настройки;

- При резком изменении цены акции после тестовой выборки, алгоритм может демонстрировать полную недееспособность, так как вычисленные на тестовой выборке параметры не будут работать на контрольной.

\section{Заключение}

Развитие торговых роботов крайне важно для финансового рынка, так как позволяет автоматизировать процесс покупки и продажи акций. Управление портфелем акций требует от человека постоянного мониторинга рынка, отслеживания различных индикаторов и своевременного изменения портфеля. В случае, если этот процесс будет максимально автоматизирован, нагрузку на человека можно свести к минимуму. Благодаря данному роботу на основе индикатора RSI, был сделан ещё один шаг к такой автоматизации.

\section{Библиографический список}

1. New Concepts in Technical Trading Systems//J. Welles Wilder, Commodities magazine (now Futures magazine), june 1978.

2. Финансовый анализ: учебное пособие//С. И. Крылов. - Екатеринбург: Изд-во Урал. ун-та, 2016. - 160 с.

3. Options, Futures, and Other Derivative Securities.//Hull J.C., 2nd ed., Englewood Cliffs, NJ: Prentice Hall, 1993.

4. Некоторые модели финансового рынка с бесконечным числом скупщиков акций. Теория вероятностей и ее применения// Шамраева В. В., 2019. Т. 64. № 1. С. 190-191.

5. Анализ финансовых рынков и торговля финансовыми активами.//М.: Питер, 2014.-240 c.

6. Мировой финансовый рынок. Тенденции развития и инструменты//Д.М. Михайлов.- М.: Экзамен, 2017.$768 \mathrm{c}$. 